\title{
APLICAÇÃO DO CONTROLE DE QUALIDADE NA BUSCA DE MINIMIZAR PARADAS NÃO PROGRAMADAS EM LINHAS DE ENVASE DE UM LATICINIO.
}

Gabriel Toledo Cardoso, João Francisco Saraiva Puglisi, Mateus Seribeli Neto, Porfirio Henrique de Sá Filho, Andréia de Menezes Olivo.

Universidade do Oeste Paulista - UNOESTE, Faculdade de Engenharia Conselheiro Algacyr Munhoz Maéder, Curso de Engenharia de Produção, Presidente Prudente - SP. E-mail: mateus.seribeli@gmail.com.

\section{RESUMO}

A satisfação do cliente é crucial para sobrevivência de uma organização, logo deve-se conquistar qualidade no produto e no processo produtivo. Para tal é preciso de planejamento para encontrar as causas que geram efeitos negativos relacionados a qualidade e funcionamento dos equipamentos. Logo, as ferramentas da qualidade são essenciais para alcançar este controle e obter a meta da organização. O presente trabalho tem como objetivo identificar o principal problema de paradas não programadas da máquina envasadora TBA/8 que opera em uma empresa de laticínio, e apurar suas causas por meio das ferramentas da qualidade. A metodologia é do tipo exploratória, descritiva e analítica e possui abordagem quantitativa-qualitativa ao mensurar os problemas ocorridos no processo de funcionamento dos equipamentos. Os resultados foram tratados com o uso de software de planilhas eletrônicas de dados utilizando modelos e técnicas estatísticas que identificaram e possibilitaram a investigação do problema e consequentes sugestões de melhoria.

Palavras- chave: Qualidade, Paradas não-programadas, Pareto, Brainstorming, Ishikawa.

\section{APPLICATION OF THE QUALITY CONTROL IN ORDER TO MINIMIZE UNSCHEDULED STOPS IN CONTAINER LINES IN A DAIRY.}

\begin{abstract}
Customer satisfaction is crucial to the organization's survival, so one must get quality in the product and in the production process. This requires planning to find the causes that generate negative effects related to the quality and operation of the equipment. Therefore, quality tools are essential to achieve this control and achieve the goal of the organization. The present work aims to identify the main problem of unscheduled stopping of the TBA / 8 filling machine that operates in a dairy company, and to investigate its causes through quality tools. The methodology is exploratory, descriptive and analytical, and it has a quantitative-qualitative approach when measuring the problems that occur in the process of equipment operation. The results were treated with the use of spreadsheets software using statistical models and techniques that identified and enabled the investigation of the problem and consequent suggestions for improvement.
\end{abstract}

Keywords: Quality, Unscheduled stops, Pareto, Brainstorming, Ishikawa. 


\section{INTRODUÇÃO}

Um dos setores que mais contribuem para a economia brasileira é o setor alimentício, representando mais de $9 \%$ do Produto Interno Bruto (PIB) do país na última década, chegando a um faturamento na ordem de 291,6 bilhões de reais em 2009 (61,7 bilhões de reais oriundos de exportações, cerca de $20 \%$ dos totais do Brasil) e responsável no mesmo ano por 1.437 .800 postos de empregos de acordo com a Associação Brasileira das Indústrias da Alimentação (ABIA, 2010). Dentre esses setores alimentícios, o segmento lácteo em 2009 ocupava a quarta posição em valor, obtendo grande destaque entre os produtos que fazem parte do agronegócio brasileiro. (SOUZA, 2011).

Com o aumento da concorrência e da exigência dos clientes passou a ser imprescindível para as organizações buscarem formas de se estabelecer e ampliar seus mercados, e a qualidade é um mecanismo que ao longo de vários anos vem sendo utilizado para tal. A qualidade dos produtos lácteos pode ser garantida através da implantação de um sistema de gestão da qualidade em toda a cadeia produtiva. A qualidade inclui a segurança alimentar, sabor, textura, odor, cor, conservação no prazo de validade, embalagem, valor nutritivo, conveniência, aparência, custo, informações no rotulo, e também os serviços associados tais como Serviço de Atendimento ao Consumidor, atendimento no ponto de venda, responsabilidade com o cliente, entre muitos outros (BRANDÃO, 2006).

O presente trabalho tem como objetivo identificar o problema que tem ocasionado maior quantidade de paradas não-programadas da máquina envasadora TBA/8, que integra o processo de envase de um laticínio, e apurar as causas destas paradas por meio da aplicação das ferramentas da qualidade. A metodologia adota uma abordagem quantitativa-qualitativa pois mensura os problemas de processo e compreende os resultados atingidos que provém dos modelos estatísticos, sendo do tipo exploratória, descritiva e analítica.

\section{QUALIDADE}

Segundo Seleme e Stadler (2010) a qualidade é um conceito desenvolvido por diversos estudiosos, também chamados gurus da qualidade, e que tem origem na relação das organizações com o mercado. Mas as considerações que com maior recorrência se fazem a respeito desse conceito são aquelas que se referem ao atendimento das necessidades dos clientes e do padrão de produção e serviços providos pela organização. A visão estratégica e competitiva das organizações, constituiu um delineamento evolutivo de abordagem da qualidade, tal evolução na concepção da qualidade é relatada como Eras da Qualidade, definidas como: Era da Inspeção, do Controle Estatístico da Qualidade, da Garantia da Qualidade e da Gestão Estratégica da Qualidade.

De acordo com Mello (2011) a Era da Inspeção trata-se da inspeção de produtos acabados, um a um, e após identificar o defeito não há nada o que fazer com ele a não ser rejeitalo, ou na melhor das hipóteses corrigi-lo até que fique conforme. Já a Era do Controle Estatístico da Qualidade consiste na inspeção dos produtos por procedimentos embasados na estatística, como a amostragem. Permanecia-se, no entanto, na esfera da inspeção de produtos prontos, apontando e mensurando os defeitos, sem apurar suas causas. A qualidade passou a ser responsabilidade somente de um setor, isolando-se dos demais agentes do processo produtivo.

Na Era da Garantia da Qualidade surgiram padrões e normas de qualidade, enfim, a ênfase passou a incidir na prevenção das inconformidades. A qualidade deixava de ser vista como responsabilidade de um departamento especifico e passa a integrar para suas frentes todos os funcionários da organização. Por fim a Era da Gestão da Qualidade Total tem como principal característica o foco no cliente e nos processos de gestão, a questão da qualidade passou a ser observada não mais como uma simples forma de prevenir defeitos e/ou redução das perdas, mas como uma maneira de agregar valor aos produtos diferenciando-se da concorrência (MELLO, 2011). 


\section{FERRAMENTAS DA QUALIDADE}

As ferramentas da qualidade são recursos com a finalidade de se ter um maior controle nos processos em sua tomada de decisão. Elas são utilizadas para definir, mensurar, analisar e propor soluções para os problemas que afetam o sistema de produção. A seguir serão descritas as ferramentas da qualidade adotadas pelo trabalho.

\section{FOLHA DE VERIFICAÇÃO}

A Folha de Verificação constitui-se em uma forma de simplificar, organizar e padronizar o recolhimento e registro de dados, para que a sequente compilação e análise das informações sejam otimizadas (WERKEMA, 2006). Existem diferentes tipos de folha de verificação, dentre eles os mais comuns são: para distribuição de um item de controle de um processo produtivo, para classificação, para localização de defeitos e para identificação de causas de defeitos. (TRIVELLATO, 2010)

\section{DIAGRAMA DE PARETO}

O Diagrama de Pareto expõe as informações de maneira que as torna clara e fácil para que então se priorize as ações, em outras palavras, hierarquiza os problemas (WERKEMA, 2006). Problemas relacionados com a qualidade, dentre eles, percentual de itens defeituosos, atrasos na entrega de produtos, modos de falhas de máquinas, perdas de produção, número de reclamações de cliente, custos com reparos de produtos dentro do prazo de garantia, ocorrências de acidentes de trabalho, que se apresentam na forma de perdas, podem ser separadas em dois grupos: os "poucos vitais" e os "muitos triviais". Sendo os poucos vitais os que mesmo sendo poucos, tem grande impacto, e os muitos triviais representam uma grande quantidade de problemas, toda via não causam impactos significativos para a organização. (TRIVELLATO, 2010)

\section{DIAGRAMA DE CAUSA E EFEITO}

O diagrama de Causa e Efeito ou Diagrama Ishikawa, é uma ferramenta empregada para explicitar a relação entre um resultado de um processo (efeito) e os fatores (causas) do procedimento que, por motivos técnicos, possam afetar o resultado apontado (WERKEMA, 2006). Atua como um guia para a identificação da causa fundamental deste problema e é utilizado para sumarizar e apresentar as possíveis causas do problema considerado, com isso, pode-se então determinar medidas corretivas para serem adotadas. (TRIVELLATO, 2010).

\section{EMPRESA}

A empresa estudada atua no setor de laticínio, atualmente está situada na região do Oeste Paulista. Dentre as eras apresentadas, ela se encontra na era da Garantia da Qualidade, pois segue padrões e normas de qualidade e tem como foco a prevenção dos defeitos. O departamento de Planejamento e Controle de Manutenção (PCM) apoia a qualidade atuando de forma preventiva e corretiva enviando à manutenção checklist's ${ }^{1}$, de acordo com horímetros individuais de cada máquina, e ordens de serviço que são disponibilizados pelo Fabricante das máquinas, que tem como função garantir o funcionamento correto do equipamento através de verificações, medições e trocas de peça pré-estabelecidas.

\footnotetext{
${ }^{1}$ Lista de Controle 


\section{PROCESSO DE FABRICAÇÃO DO LEITE E O USO DAS MÁQUINAS ENVASADORAS}

$O$ processo produtivo do leite se subdivide de forma macro do seguinte modo: recebimento da matéria prima, pasteurização/padronização, produto em processo e por fim produto acabado. Dentro da etapa produto em processo situa-se o objeto de estudo, a máquina de envase TBA $/ 8$, que possui capacidade de envase de $6000 \mathrm{l} / \mathrm{h}$ em média e é abastecida por bobinas de embalagens sendo composta por 6 camadas: 4 de polietileno, 1 de alumínio e 1 de papel-cartão, que garantem a hermeticidade da embalagem. Posteriormente a embalagem passa pelo sistema vincador para auxiliar no processo de formação da embalagem e na etapa conseguinte é aplicada a Fita de Poliestireno que servirá de apoio para a selagem e fechamento longitudinal da embalagem. Em seguida é mergulhada em peróxido de hidrogênio $(\mathrm{H} 2 \mathrm{O} 2)$ a $80^{\circ} \mathrm{C}$, que garante a esterilização interna e externa, e imediatamente é retirado todo excesso deste por um sistema de rolos espremedores e uma faca de ar a 130 드, seguindo assim para os anéis de formação e soldadura longitudinal, que por fim entram no tubo de enchimento, no qual o produto é envasado, passando assim pelas mandíbulas de corte que, através de um sistema de correção, formam a altura exata do produto final, que adiante é levado para a Pregadora final, onde o produto final é formado e selado, alimentando assim a próxima etapa do processo.

\section{RESULTADOS E DISCUSSÃO}

A coleta de dados do presente estudo, foi realizada baseada em folhas de verificação dentro do período de dezembro de 2016 a fevereiro de 2017, estas têm por objetivo oferecer o maior número de dados para que possam sofrer um tratamento estatístico e oferecer respostas orientadoras para a melhoria do processo. Com a obtenção de uma vasta quantidade de dados foi utilizado o Diagrama de Pareto exemplificado na Figura 1, pois permite realizar uma hierarquização dos problemas, indicando qual destes impacta de forma mais significativa nas quantidades de paradas de máquina.

Figura 1. Diagrama de Pareto dado pela frequência de ocorrência das paradas em relação as causas das paradas da Máquina de Envase

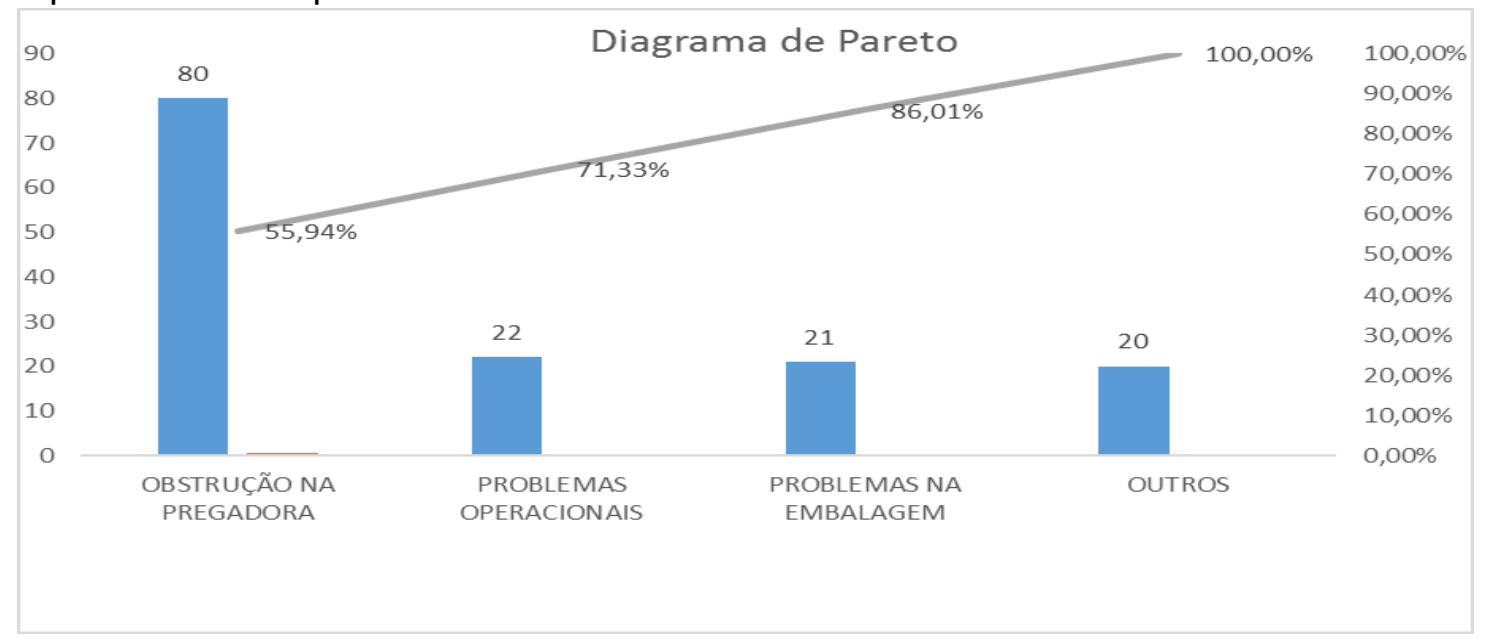

Fonte: Autoria Própria

Por meio do diagrama é notável que o problema Obstrução na Pregadora gerou a maior quantidade de paradas não-programadas, representando $55,94 \%$ da frequência acumulada, fazendo deste o foco do trabalho na apuração de suas causas.

O brainstorming foi realizado com a participação de um grupo de alunos e um Técnico de Manutenção da empresa para buscar quais as causas principais e mais relevantes do problema estudado que é a obstrução na pregadora. Foram levantadas quatro possíveis principais causas 
deste problema, sendo elas: Falha na soldadura de abas, Embalagem deformada, Falha de Sincronismo e Posição incorreta da Embalagem.

A Falha na soldadura de abas ocorre quando estas não são soldadas corretamente, este tipo de falha pode ser causado tanto pela queima da resistência quanto por uma posição incorreta nos bicos responsáveis pela soldadura. A embalagem pode deformar-se devido a incorretos ajustes finos durante a produção. Já a falha no sincronismo é resultado de incorretos ajustes mecânicos, elétricos e de desgastes das peças da máquina. Por fim uma Embalagem em Posição Incorreta na estação de saída provém de transportadores de corrente quebrados que impossibilita o transporte correto da embalagem, de cortes incorretos da embalagem na mandíbula e de atrasos na abertura da calha.

Figura 2. Brainstorming

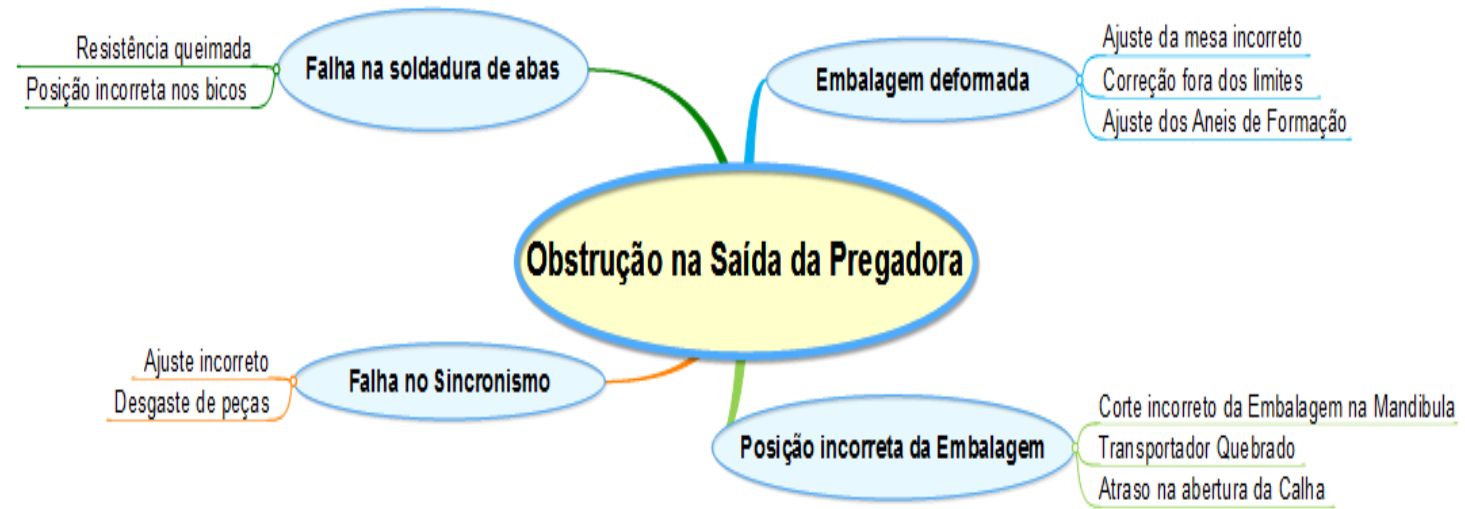

Fonte: Autoria própria

Com o auxílio do brainstorming foram determinadas possíveis causas primárias e secundárias para o efeito estudado e mediante estas informações viabilizou-se a construção do Diagrama de Causa e Efeito, também conhecido como Diagrama de Ishikawa.

Figura 3. Diagrama de Ishikawa

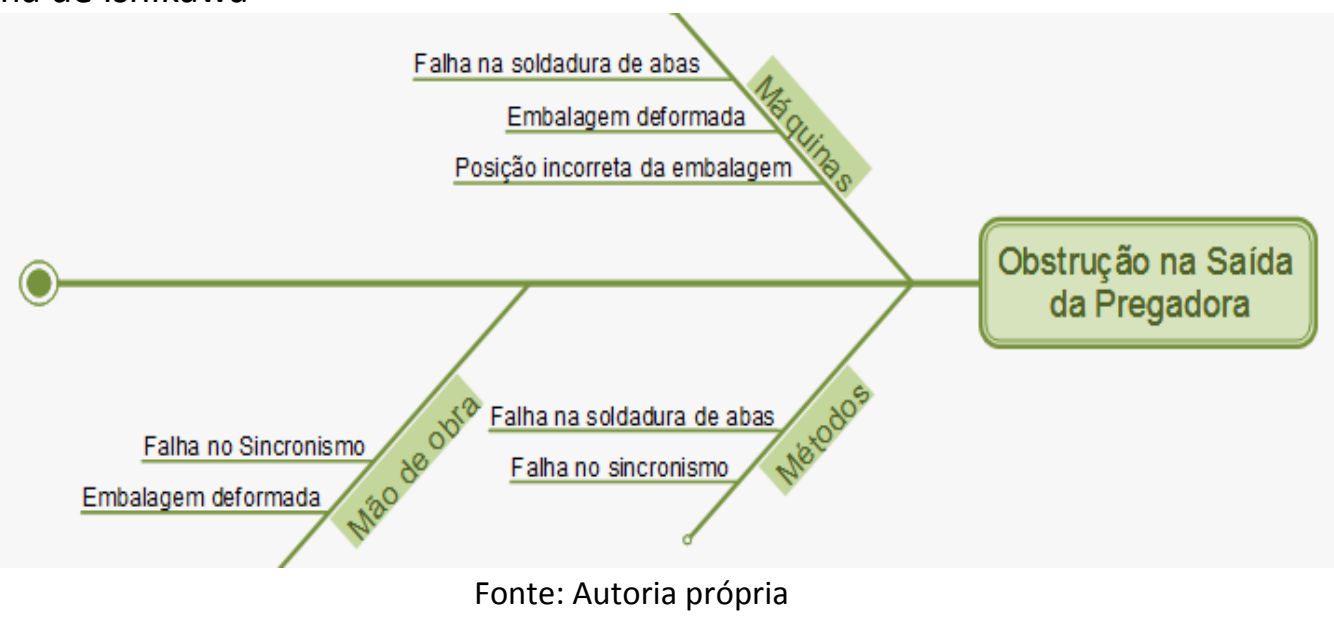

A causa Falha na soldadura de Abas é inclusa nas categorias Métodos e Máquinas, pois ela pode ser provocada por uma queima de resistência que está ligada aos métodos de como a mesma é instalada ou trocada, bem como está relacionada a Máquinas, devido a posição incorreta dos bicos de soldadura ser gerada por falhas advindas do funcionamento da máquina. Também inserida em duas categorias tem-se a Embalagem Deformada, classificada como Máquinas em razão de correção fora dos limites, e está classificada em mão de obra pois os ajustes finos 
operacionais de mesa e dos anéis de formação quando feitos incorretamente também provocam esse defeito.

Outra causa com dois diferentes tipos de classificação é a Falha no Sincronismo, que pode ser resultada por um desgaste de peças, que se não for feito acompanhamento e uma troca preventiva então torna-se um problema, por essa razão foi listada como Método. E um ajuste incorreto, fora do gabarito ou não bem executado, é especificado como Mão de Obra. Por fim a causa Posição incorreta de embalagem é apenas incluída no quesito Máquinas, pois o Corte incorreto da Embalagem na Mandíbula surge de problemas mecânicos no sistema de mandíbulas.

\section{CONSIDERAÇÕES FINAIS}

As operações produtivas são propensas a falhas e constantemente se busca a minimização das mesmas em razão de altos custos pela ausência de qualidade, e as empresas passaram a observa-la como um problema que necessitava ser enfrentado. Em vista disso o presente trabalho almejou levantar as principais causas dos problemas de parada da máquina de envase TBA/8.

Com a aplicação das ferramentas da qualidade o trabalho pode constatar que a obstrução na pregadora é o problema mais frequente de parada da máquina de envase, correspondendo a $55,94 \%$ das paradas ocorridas durante o processo de envase, indicando assim sua prioridade em relação aos outros. A partir do momento que se identifica a disfunção principal, causas podem ser levantadas e ações são possíveis de serem feitas.

Em vista das causas levantadas que foram classificadas nas categorias máquinas, métodos e mão de obra o trabalho sugere primeiramente para a eliminação da causa de mão de obra, que a empresa forneça treinamento aos seus colaboradores que operam a máquina TBA /8 bem como aos seus manutentores. Já relacionados aos métodos proponha-se que os responsáveis pela elaboração das instruções de operação as revisem, com o intuito de reduzir as quebras nãoprogramadas. Tal sugestão se justifica, uma vez que para a organização a conquista da qualidade em suas operações apresenta-se de forma significativa, pois auxilia em diversos aspectos sendo alguns deles o aumento da produtividade e consequente redução dos custos de operação.

\section{REFERÊNCIAS}

ABIA (Associação Brasileira das Indústrias da Alimentação). Ficha Técnica. Disponível em: <http://www.abia.org.br/anexos/FichaTecnica.pdf>. Acesso em: 24 mar 2017.

BRANDÃO, S.C.C. Fundamentos da Busca pela Qualidade na indústria. In: MESQUITA, A.J., DÜRR, J.W., COELHO, K.O. (Org.) Perspectivas e Avanços da Qualidade do Leite do Brasil. 1 ed. Goiânia: Talento, 2006, v. 1, p. 291-326.

MELLO, C. H. P.; Gestão da Qualidade. São Paulo: Pearson Education do Brasil, 2011.

SELEME, R.; STADLER, H. Controle de Qualidade: As ferramentas essenciais. 2. ed. Curitiba: Ibpex, 2010.

SOUZA, J. J. Notas sobre a indústria de laticínios no Brasil e seu processo de formação perante a economia mundial. CaderNAU - Cadernos do Núcleo de Análises Urbanas, v. 6, n. 1, 2013. Disponível em: <https://www.seer.furg.br/cnau/article/view/4768>. Acesso em: 24 mar 2017.

TRIVELlATO, A. A. Aplicação das Sete Ferramentas Básicas da Qualidade no Ciclo PDCA para melhoria continua: estudo de caso numa empresa de autopeças. 2010. 72 p. Trabalho de 
Conclusão de Curso - Escola de Engenharia de São Carlos, Universidade de São Paulo, São Carlos, 2010.

WERKEMA, M. Ferramentas estatísticas básicas para o gerenciamento de processos. Belo Horizonte: Werkema Editora Ltda, 2006. 